\title{
En la ciudad de Madrid todos los caminos conducen a Airbnb
}

\section{In the city of Madrid all roads lead to Airbnb}

María Antonia Martínez-Caldentey iD, Universitat de les Illes Balears, España maria.martinez.caldentey@gmail.com

Ivan Murray iD, Universitat de les Illes Balears, España

ivan.murray@uib.es

Macià Blázquez-Salom (iD, Universitat de les Illes Balears, España

mblazquez@uib.cat

\section{RESUMEN}

Desde el estallido de la crisis global en 2008, la turistización de la economía española se ha intensificado. La ciudad de Madrid, en este contexto, también ha ganado poder como espacio turístico. El artículo analiza las tensiones entre el alquiler turístico y el alquiler residencial en la ciudad de Madrid. Este estudio se ha realizado mediante técnicas de análisis espacial, estadísticas y cartográficas, que nos permiten visualizar y cuantificar las variables relacionadas con el alquiler turístico y residencial en la ciudad. Aunque es cierto que en la actualidad la oferta de alquiler turístico está presente en cada uno de los distritos de Madrid, siguiendo un patrón espacial en forma de mancha de aceite, es en el casco histórico donde se concentran más de la mitad del total de ofertas gestionadas mediante Airbnb. Este artículo tiene como objetivos: 1) establecer los patrones espaciales del alquiler turístico, basados en el análisis de una muestra de ofertas de Airbnb en la ciudad de Madrid; 2) estimar la distribución espacial del alquiler residencial, así como, donde se enfrenta con el alquiler turístico; 3) evaluar los efectos de las medidas regulatorias del uso turístico de viviendas. El estudio ha concluido que el alquiler turístico llevado a cabo en la ciudad de Madrid sigue un patrón de explotación intensiva, donde el casco histórico es el núcleo de dicha actividad, siendo donde existe la mayor confrontación entre el alquiler residencial y el alquiler turístico.

Palabras clave: Airbnb; alquiler turístico; alquiler residencial; distribución espacial; Madrid. 


\section{ABSTRACT}

Since the outbreak of the global crisis in 2008, the touristification of the Spanish economy has intensified. Within this context, the city of Madrid has also gained power as a tourist destination. The paper analyses the tensions between tourist rental and residential rental in the city of Madrid. This study was carried out using spatial analysis, statistics and cartographic techniques, enablaing us to visualize and quantify the variables related to tourist and residential rental activity in the city. Although it is true that today there are tourist rental properties in every district of Madrid following a spatial pattern in the form of an oil stain, it is in the old town where more than the half of the total of tourist rental properties offered on Airbnb are located. This paper aims to: 1 ) establish the spatial patterns of tourist rental activity, based on the analysis of a sample of Airbnb's offer, in the city of Madrid; 2) estimate the spatial distribution of residential rental properties and identify where they clash with tourist rentals; 3 ) evaluate the effects of the regulatory measures related to the tourist use of homes. The study concludes that the tourist rental business carried out in the city of Madrid follows a pattern of intensive exploitation, where the old town is the nucleus of this activity, constituting the place of greatest confrontation between the residential rental and the touristic rental markets.

Keywords: Airbnb; tourist rental; residential rental; space distribution; Madrid.

\section{NTRODUCCIÓN}

La ciudad de Madrid, erigida bajo la capitalidad político-administrativa, se constituye como una amalgama de funciones empresariales, socioeconómicas y turísticas, éstas últimas en pujante crecimiento. La confluencia y el choque entre tales funciones implica fuertes tensiones entre el valor de uso y el de cambio del territorio, particularmente del entorno construido, a raíz de su mercantilización a través de la propiedad privada, siendo un pilar fundamental del capitalismo.

Tras la crisis inoculada por la pasada burbuja inmobiliaria, detonada en 2008 , los procesos e intereses especulativos relacionados con la vivienda han vuelto a resurgir. El capitalismo financiero y de plataforma han apresado multitud de viviendas, mediante desahucios, acaparamiento de propiedades y cambio de uso de residencial a turístico. Buena muestra de ello es la venta de viviendas de propiedad pública a fondos de inversión, «fondos buitre» (como, por ejemplo, del Ayuntamiento de Madrid a Blackstone en 2013ㄹ) o la comercialización de viviendas para el alojamiento turístico por parte de plataformas, especialmente Airbnb.

El alquiler turístico, auspiciado mediante el capitalismo de plataforma, ha catalizado la explotación de la vivienda a través de su valor de cambio alrededor de todo el globo, mientras que el valor de uso, el cual permite establecerse como un hábitat para las personas, es relegado a un segundo plano. Sobre todo, en casos como el de la ciudad de Madrid, donde la

1. Público (24/04/2019). «El fondo buitre Blackstone comienza a hacer negocio con las viviendas sociales de Madrid que le vendió Ana Botella». Público. Disponible online: https://www.publico.es/economia/blackstone-fondobuitre-blackstone-pretende-vender-viviendas-sociales-compradas-madrid.html (consultado el 22/05/2019). 
actividad llevada a cabo por Airbnb se encuentra alejada de la economía colaborativa (Gil y Sequera, 2018).

El estudio que aquí se presenta pretende: 1) establecer los patrones espaciales del alquiler turístico de viviendas, a partir del análisis de una muestra de la oferta de Airbnb, en el municipio de Madrid; 2) estimar la distribución espacial del alquiler residencial, así como dónde se confronta con el alquiler turístico; y 3 ) evaluar los efectos de las medidas regulatorias del uso turístico en viviendas.

La oferta del alquiler turístico se ha estudiado a través de los alojamientos ofertados en una única plataforma, como es Airbnb, siendo la pionera de entre ellas. Buceando en la espacialidad de la ciudad de Madrid, se percibe que las ofertas del alquiler turístico siguen un patrón espacial muy definido, en forma de mancha de aceite. Esta particular distribución espacial del alquiler turístico se distingue de otras ciudades europeas por la gran concentración de este fenómeno en un espacio muy reducido, como es el casco histórico de la ciudad, conocido como distrito Centro.

El análisis del alquiler de larga duración ha bebido tanto del censo de 2011, como de una muestra tomada en 2018 de portales inmobiliarios especializados. Con ello se ha conseguido extraer información sobre la distribución espacial de las viviendas destinadas al alquiler residencial en todos los distritos de la ciudad de Madrid.

En cuanto a la regulación, esta mantiene una tendencia a liberalizar el uso de viviendas para el alojamiento turístico, con un breve paréntesis del Plan Espacial de Regulación del Uso de Servicios Terciarios en la clase de Hospedaje (PEH, en adelante; B.O.C.M., 23/05/2019).

El artículo se ha construido en base a una estructura que comienza con las preguntas de investigación propuestas; a continuación, se plantea la metodología que se ha seguido para llevar a cabo el estudio, la cual se ha integrado en la vía cuantitativa del positivismo radical (Wyly, 2011). En cuanto al contexto teórico, este se enmarca en la profundización de la concepción de la ciudad en crisis, siendo el continente de la actividad turística estudiada. A continuación, se presenta la situación de Airbnb en el contexto del estado español, y en concreto de la ciudad de Madrid. Además, en el mismo apartado también se ha retratado la difusión espacial del alquiler turístico comercializado mediante Airbnb, así como su incidencia sobre los precios del alquiler residencial. Mientras que finalmente, se repasa la ordenación y la regulación del alquiler turístico de las viviendas en la ciudad de Madrid. Por último, se encuentran las conclusiones extraídas a partir del estudio llevado a cabo.

\section{METODOLOGÍA}

El plano de estudio que sostiene a este artículo es la espacialidad, es decir, el territorio donde se ancla el capital a través de la mercantilización de los inmuebles, y cuya insaciabilidad por rentabilizar económicamente todo aquello que se sostenga sobre la tierra, ha dado a luz a una nueva forma de explotación capitalista, como es el alquiler turístico masivo de viviendas. De todo ello, se plantean las siguientes preguntas de investigación: ¿bajo qué tipo de distribución espacial se ha desarrollado Airbnb en la ciudad de Madrid?; ¿cuál es la orientación 
espacial a la que tiende el futuro desarrollo del alquiler turístico en Madrid?; ¿en qué barrios de la ciudad se produce la mayor confrontación entre el alquiler turístico y el alquiler residencial?; y, finalmente, ¿̇es la regulación actual de las VUT en Madrid suficiente para garantizar la protección del uso residencial?

El presente trabajo se ha construido sobre la base de técnicas cuantitativas combinando el análisis estadístico y cartográfico. El estudio de la situación de la vivienda en la ciudad de Madrid se ha llevado a cabo mediante el uso de indicadores procedentes de fuentes oficiales, como son el banco de datos del Ayuntamiento de Madrid, el Catastro y el Censo de 2011. Además, también se ha recolectado información de fuentes privadas, como por ejemplo los datos del portal especializado en el mercado inmobiliario español: Idealista.

En primer lugar, se ha analizado la evolución de los precios del alquiler residencial para cada uno de los distritos de la ciudad de Madrid entre 2007-2018. El periodo de estudio se ha establecido tomando como inicio el estallido de la pasada burbuja inmobiliaria, el sucesivo valle alcanzado por la regresión de los precios, y su posterior elevación a partir de 2015, momento de irrupción en los mercados por grandes flujos de inversión extranjera y de la compra masiva de deuda púbica -quantitative easing-por parte del $\mathrm{BCE}^{2}$. Tal información ha sido extraída a través del portal estadístico del Ayuntamiento de Madrid, el cual se recoge como la evolución de la renta mensual de la vivienda en alquiler por distrito (euros $/ \mathrm{m}^{2}$ construido). Cabe decir igualmente, que el banco de datos del Ayuntamiento de Madrid se nutre de la información recopilada por el portal inmobiliario Idealista. El portal inmobiliario ha conseguido hacerse con este tipo de información, recolectándola, tratándola y publicándola para el conjunto del territorio español. Al desentenderse de tal responsabilidad la administración pública, cualquier estudio o aproximación que se quiera hacer sobre la vivienda se encuentra a merced de la visión que quieran dar las empresas privadas que explotan económicamente este sector.

En segundo lugar, se ha recurrido a la información recogida por los portales de InsideAirbnb y DataHippo para estudiar el alquiler turístico y su comparación con el alquiler residencial. A partir de estas fuentes se ha realizado una base de datos propia mediante hojas de cálculo. Tras el tratamiento de la información se ha procedido a su volcado sobre ArcGIS, de forma que se tradujeran los datos numéricos en información espacial.

En cuanto a las operaciones de análisis espacial, se ha optado por un seguido de herramientas contenidas en ArcGIS:

- Optimized Hot Spot Analysis. El análisis de puntos calientes optimizado consiste en una evaluación de las entidades dadas en base a la estadística Gi* de Getis-Ord, dando como resultado cuales son los puntos calientes y fríos estadísticamente significativos del total de las entidades analizadas.

- Índice I de Moran para analizar la autocorrelación espacial en base a la ubicación de las entidades estudiadas, dando como resultado el nivel de dispersión o concentración de estas.

2. El BCE finaliza el 'QE' después de casi 4 años. https://www.eleconomista.es/mercados-cotizaciones/noticias/ 9594509/12/18/El-BCE-finaliza-el-QE-despues-de-casi-4-anos.html 
- Directional Distribution (Standard Directional Ellipse). La distribución direccional mide la tendencia en la dirección y la orientación de una distribución espacial de entidades dada.

- Centro medio ponderado. El centro medio proporciona los promedios de los centroides mediante los valores $\mathrm{X}$ e $\mathrm{Y}$ de los datos dados, de forma que, de una nube de puntos como entrada, da como resultado un único punto de la media ponderada.

En tercer lugar, se han estudiado el marco regulatorio y el planeamiento, para evaluar las políticas de ordenación urbano-turística de la Comunidad y del municipio de Madrid. Ello se ha hecho a través del análisis del Decreto 79/2014, de 10 de julio, por el que se regulan los apartamentos turísticos y las viviendas de uso turístico de la Comunidad de Madrid, así como mediante el estudio del Plan Especial de Regulación del uso de Servicios Terciarios en la clase de Hospedaje (PEH) del Ayuntamiento de Madrid.

Finalmente, cabe decir que el acceso a la información ha sido el mayor obstáculo para la realización de este trabajo, sobre todo en lo tocante a la situación inmobiliaria. Los datos públicos más recientes de la administración sobre el volumen de viviendas arrendadas se basan en el Censo de 2011, por lo que los datos son poco robustos a la hora de intentar conocer la situación del alquiler residencial actual (Palacios, 2008), así como su interacción con el alquiler turístico. Por ello, si se quiere analizar la cantidad de inmuebles que operan como arrendamientos de larga duración se debe recurrir a fuentes no oficiales y metodologías hacker, concretamente el web scraping de páginas en internet de portales inmobiliarios. Asimismo, los datos sobre los precios de la compraventa de viviendas y del alquiler se encuentran igualmente en manos de empresas privadas. De hecho, la propia administración pública recurre a tales portales inmobiliarios, como Idealista, para obtener la información inmobiliaria en la actualidad. Por lo que todo análisis que se quiera hacer sobre el estado de la vivienda depende de la información prestada por empresas privadas, asegurándose así tener el monopolio y el control de los datos que resultan vitales para el conocimiento profundo y detallado de la cuestión de la vivienda. Ello, limita a su vez, la calidad de cualquier estudio analítico al respecto, así como la capacidad de las administraciones públicas para llevar a cabo políticas de vivienda sólidas. El hecho que las inmobiliarias, que sacan su rédito económico a partir de la explotación del mercado inmobiliario, sean los principales organismos que recogen, recopilan y tratan la información inmobiliaria del país, hace que los ciudadanos y la propia administración pública se encuentren a su merced; además de depender de la visión que estas empresas privadas nos quieran dar sobre la cuestión de la vivienda (Palacios, 2008).

En cuanto a la información sobre el alquiler turístico, la administración pública de nuevo se encuentra desnuda, de forma que la información disponible depende de colectivos que, siguiendo la filosofía hacker, han decidido arrojar algo de luz sobre la opacidad de la que hacen gala Airbnb y compañías similares. Bajo tales preceptos, el alquiler turístico ha sido analizado a través de los datos extraídos de InsideAirbnb y DataHippo, sin los cuales hubiera sido imposible retratar el volumen y la distribución espacial del alquiler turístico. 


\section{MARCO TEÓRICO Y ÁMBITO DE ESTUDIO. LA CIUDAD EN CRISIS}

Si bien en su día Lefebvre (1968) encontró necesario partir de los efectos producidos por el proceso de la industrialización para comprender la problemática urbana, hoy en día se debe analizar desde la financiarización y la terciarización de la ciudad, siendo el turismo uno de sus pilares, favoreciendo la atracción de capital extranjero para su fijación en el espacio, así como la especulación inmobiliaria (Blanco, Blázquez-Salom y Cànoves, 2018).

La financiarización y terciarización de la economía ha profundizado ${ }^{3}$ lo que ya observó Lefebvre en la ciudad de los años sesenta donde la composición de obra (ouvre en el sentido de creación colectiva del espacio urbano) se iba abandonando al dejar de lado su valor de uso. Lo que la convierte en una mercancía, explotando su valor de cambio, a la vez que lo urbano interviene como tal en la producción (Lefebvre, 1968; Morell, 2018). Las ciudades pasan así, de ser el nicho de la producción de bienes, a ciudades de artificio y espectáculo. Es decir, las ciudades son una potente mercancía (Del Romero, 2010).

Las ciudades devienen como unos contenedores turísticos más, esparcidas alrededor del globo y complementando la oferta turística, la cual ha conseguido llegar a cada rincón del planeta gracias al transporte y la tecnología que lo acompaña (Cabrerizo, 2016; Milano y Mansilla, 2018). Asimismo, el turismo se ha convertido en la principal arma para acaparar el tiempo libre, que bajo el sistema neoliberal, se configura cuasi-exclusivamente como un momento para el consumo. Además, el turismo también se vende como un paliativo para la alienación laboral, permitiendo degustar experiencias que pretenden beber de las aguas del hedonismo (Harvey, 2014). Sin embargo, esas experiencias se tornan a menudo en vivencias recreadas sobre escenarios impostados bajo la tutela de actores autóctonos alienados que recrean una parca fantasía (Gil, 2019).

El acondicionamiento de la ciudad para hacerla más atractiva de cara a los visitantes suele tender a dejar siempre de lado a las mismas variables: los residentes y su vida cotidiana (Cabrerizo, 2016; Colomb y Novy, 2016). De hecho, cuando la concienciación de las contradicciones provocadas por la actividad turística se revela en un territorio turísticamente explotado, la reacción de los poderes en favor de esta industria es instantánea y mordaz, tal como demuestra la proliferación del vocablo: turismofobia (Blanco et al., 2019). Una palabra utilizada usualmente por los actores pro-turísticos y beneficiarios del mismo para señalar y demonizar comportamientos y colectivos que supuestamente demuestran aprensión hacia la figura del turista. Sin embargo, la proliferación de dicho término pone en evidencia la lógica post-política asociada al turismo que se presenta como algo natural, propio de la vocación del territorio. En cualquier caso, la aparición de movimientos críticos con el turismo ha contribuido a la politización de la cuestión turística (Cañada y Murray, 2019). El radio de acción de la actividad turística urbana suele acotarse a los límites del casco histórico y sus alrededores, porque en el imaginario colectivo es en estas zonas urbanas donde se concentra la esencia de la ciudad. De ello se obtienen paisajes culturales escenificados, donde el patrimonio urbano pasa a conformar las principales atracciones turísticas, además de entrar en disputa los usos

3. Para un análisis en profundiad sobre la geografía de la financiarización véase Aalbers (2015), Christophers et al. (2017) y Méndez (2018). 
del espacio urbano, encontrándose en medio del uso cotidiano de los residentes y del uso por el placer de los turistas (Cabrerizo, 2016; Morell, 2018).

El caso del distrito Centro, de la ciudad de Madrid, resulta ejemplar en la turistificación del casco antiguo de una urbe (Valenzuela, 1999). Su patrimonio monumental resulta ser pasto de los visitantes, como el Palacio Real, la Catedral de la Almudena y los Jardines de Sabatini. Mientras que otros lugares han resultado ser homogeneizadores de habitantes y turistas por el tipo de transformación productiva: Gran Vía, Callao y Sol convertidos en zonas comerciales en horario diurno; así como La Latina, Malasaña y Chueca convertidos en zonas de ocio nocturnas. Por último, también se dan zonas donde la disputa por el espacio entre residentes y visitantes es más notable, sobre todo con la irrupción del alquiler turístico, siendo Lavapiés ${ }^{4}$ el escenario donde se pueden observar con mayor intensidad tales tensiones (Gil y Sequera, 2018).

Por otra parte, los centros urbanos basados en la mercantilización de lo urbano y lo cultural bajo una elevada especialización turística, -la cual recibe las inversiones del sector privado, pero también de concesiones públicas- no genera necesariamente incrementos en la calidad de vida de la población, ni produce notables subidas en la renta de los habitantes, así como tampoco favorece la calidad de los servicios de salud, educación o el acceso a la vivienda para los residentes; mientras que el nivel de ingresos de los mismos se mantiene bajo al distribuirse de forma inversamente proporcional a la penosidad del trabajo realizado (Cabrerizo, 2016; Cañada y Murray, 2019; Naredo, 2006).

La ciudad en crisis se erige finalmente así sobre la contradicción de la naturaleza de lo urbano como valor de uso y la imposición del capital, en el cual se lleva a cabo la explotación del valor de cambio (Harvey, 2014). En definitiva, de acuerdo con Fletcher (2011) podemos sostener que el turismo ha sido una pieza clave en la solución de la crisis de 2008, y que además bajo las recientes lógicas espaciales del capital turístico, las ciudades juegan un lugar destacado (Colomb y Novy, 2016). En el seno de las ciudades, la vivienda, que había estado en el centro del ciclo de acumulación que ocasionó la crisis de 2008 , se ha convertido en la nueva frontera de mercantilización turística. Los procesos de mercantilización turística de la vivienda, definido como airbnbificación, han sido uno de los campos más recientes de la conflictividad urbana, así como un campo de debate y análisis académico vibrante (Cócola-Grant, 2019; Milano y Mansilla, 2019; Quagleri y Sánchez, 2019).

\section{LA TOMA DE LA VIVIENDA: AIRBNB EN ESPAÑA Y EN LA CIUDAD DE MADRID}

Nuestro análisis se concentrará en la presentación de los resultados referentes a: primero, la singularidad madrileña en el contexto español; segundo, la evolución del proceso de difusión espacial del alquiler turístico de viviendas mediante la plataforma Airbnb; tercero, su incidencia sobre los precios del alquiler residencial; y, por último, la ordenación y regulación del alquiler turístico de viviendas.

4. Manifestaciones de tales luchas se encuentran en la formación de colectivos como Lavapiés ¿dónde vas? (https://lavapiesdondevas.wordpress.com/), el cual se encuentra en lucha por la permanencia de los vecinos y en contra de la presión ejercida por el turismo que invade el barrio. 


\subsection{La singularidad madrileña en el contexto español}

La expansión espacial de Airbnb en la actualidad alcanza gran parte de las ciudades de todo el globo. Empero, es en las ciudades del continente europeo donde Airbnb tiene el mayor volumen de alojamientos ofertados, estando París y Londres a la cabeza (Crommelin et al., 2018; Gurran, 2018). En el caso particular de España, si bien a nivel de ciudad, son las metrópolis de Barcelona y Madrid donde se concentra la mayor actividad de Airbnb, es interesante desplazarse hasta el nivel provincial para comprobar en qué territorios se aglutina esta actividad.

Tal como puede apreciarse en la figura 1, la intensidad de la explotación del alquiler turístico se correlaciona con aquellos territorios donde el turismo es predominante, como en las costas del mediterráneo. El peso de la oferta de Airbnb se concentra así en las provincias de Barcelona, Málaga, Alacant, Illes Balears, Madrid, Girona, Las Palmas, Santa Cruz de Tenerife, València, Cádiz, Tarragona y Sevilla. Por su parte, el volumen medio de la oferta de Airbnb se localiza en las provincias litorales de todo el Estado, como: Granada, Asturias, Murcia, Castellón, Cantabria, A Coruña y Gipuzkoa. Mientras que el menor peso de la oferta de Airbnb se concentra en las provincias del interior, conformando una corona intermedia entre Madrid y las provincias litorales. Así, el mapa de Airbnb reproduce el mismo patrón de la división regional del trabajo de España (Carpintero, 2015).

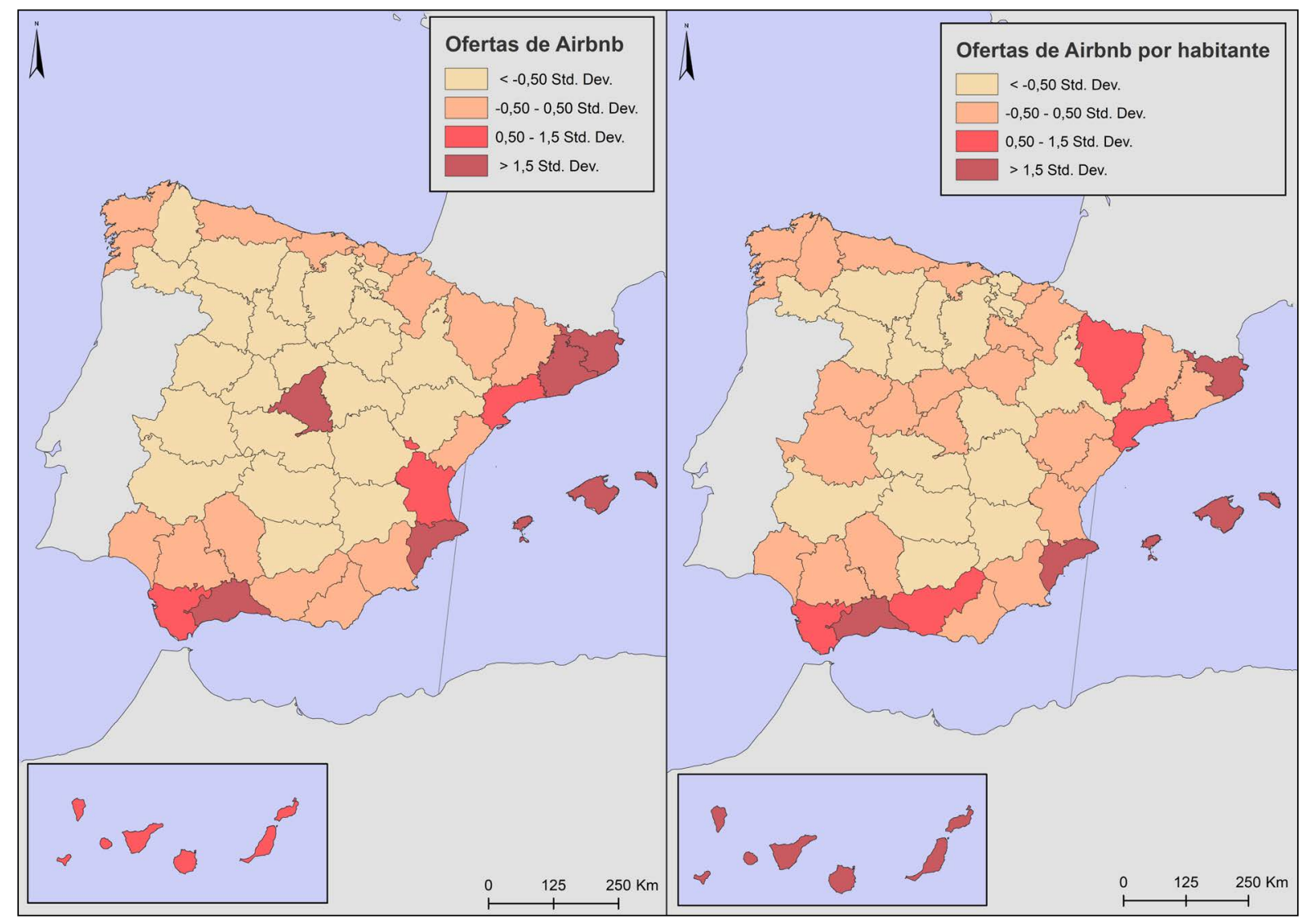

Figura 1. Volumen de la oferta de Airbnb en las provincias del Estado español. Fuente: elaboración propia a partir de datos extraídos en junio de 2018 en DataHippo. 


\subsection{La difusión espacial del alquiler turístico de viviendas mediante Airbnb}

La ciudad de Madrid alberga un total de 22.909 ofertas de viviendas turísticas solo en Airbnb. De ellas, el 60,60\% son viviendas enteras, el 37,85\% corresponden a habitaciones privadas, mientras que el $1,55 \%$ representa la oferta disponible de habitaciones compartidas ${ }^{5}$.

Por otra parte, se ha analizado la difusión de la oferta del alquiler turístico comercializada bajo Airbnb a partir de un paquete de datos del portal InsideAirbnb ${ }^{6}$. Los resultados de la difusión de Airbnb se presentan en la figura 2, donde se puede contemplar la expansión espacial de Airbnb en la ciudad de Madrid, desde sus inicios en 2010, pasando por su consolidación, hasta llegar a los años más recientes, mostrándose en 2018 la basta magnitud que ha alcanzado este fenómeno.

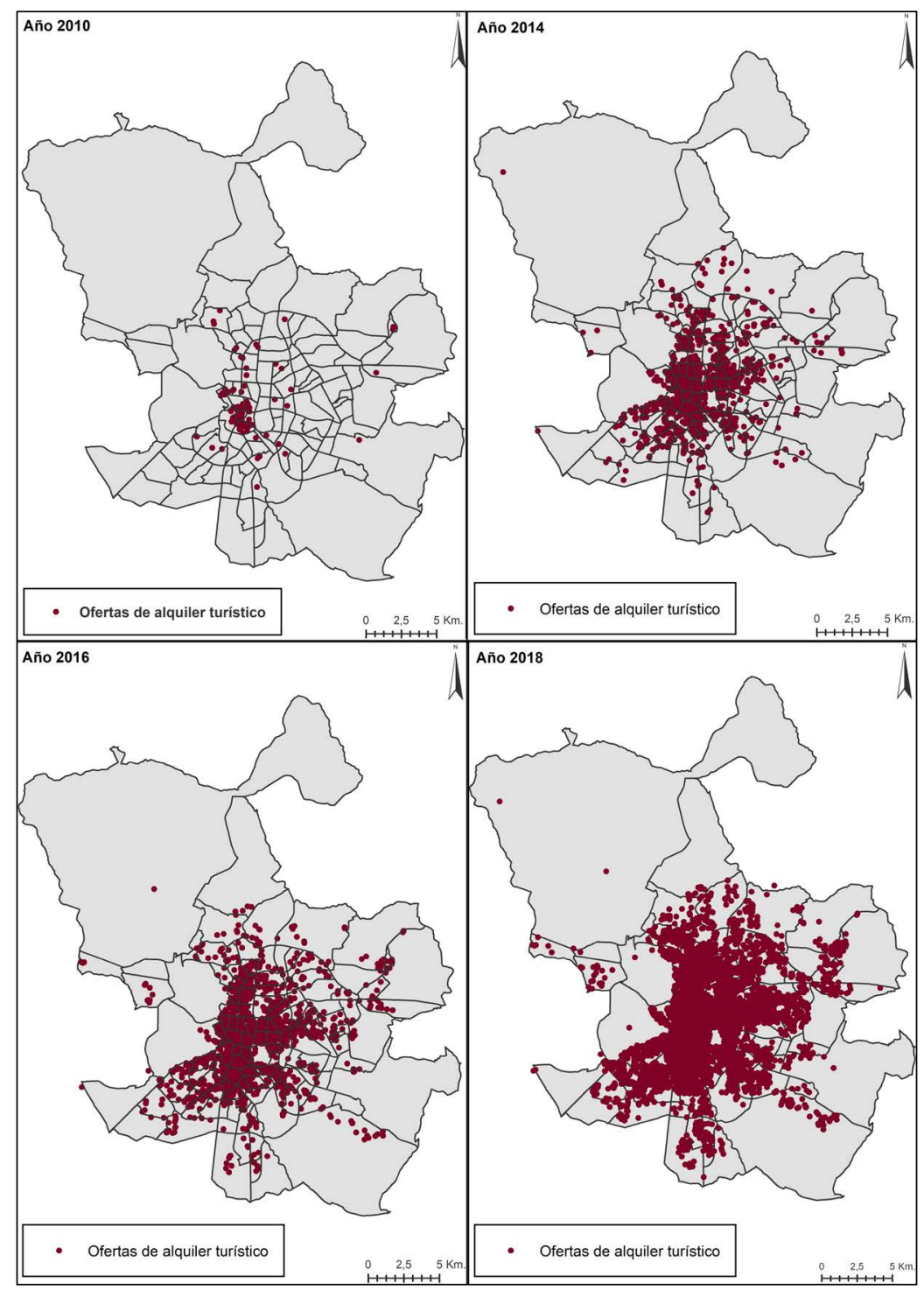

Figura 2. Mapas sobre la evolución del alquiler turístico ofertado en Airbnb en la ciudad de Madrid, años 2010, 2014, 2016 y 2018. Fuente: elaboración propia a partir de InsideAirbnb.

5. Datos recogidos en DataHippo a día 20 de junio de 2018.

6. Datos publicados por InsideAirbnb para Madrid en mayo de 2018. 
Si bien es cierto que hay ofertas de alquiler turístico en cada uno de los distritos del municipio de Madrid, la densidad de dichos alojamientos varia ampliamente (ver figura 3). Ejemplo de ello es el distrito de Moncloa-Avaraca, donde Airbnb muestra una presencia notable en Argüelles, mientras que en el resto de los barrios la densidad de alquiler turístico es bajo. Al tomar la densidad de alojamiento turístico por la superficie, se puede observar cómo se concentra en los barrios de Centro, en Argüelles, Trafalgar y Palos de Moguer. Mientras que a su alrededor se dibuja una segunda corona de densidades medias acogiendo los barrios situados al noreste y al sur del distrito Centro, entre los cuales destacan: Gaztambide, Goya, Arapiles, Ibiza, Lista, Recoletos, Pacífico, La Chopera, Las Acacias, Almagro, Castellana, Castillejos, Puerta del Ángel, Bellas Vistas, Delicias y Comillas.

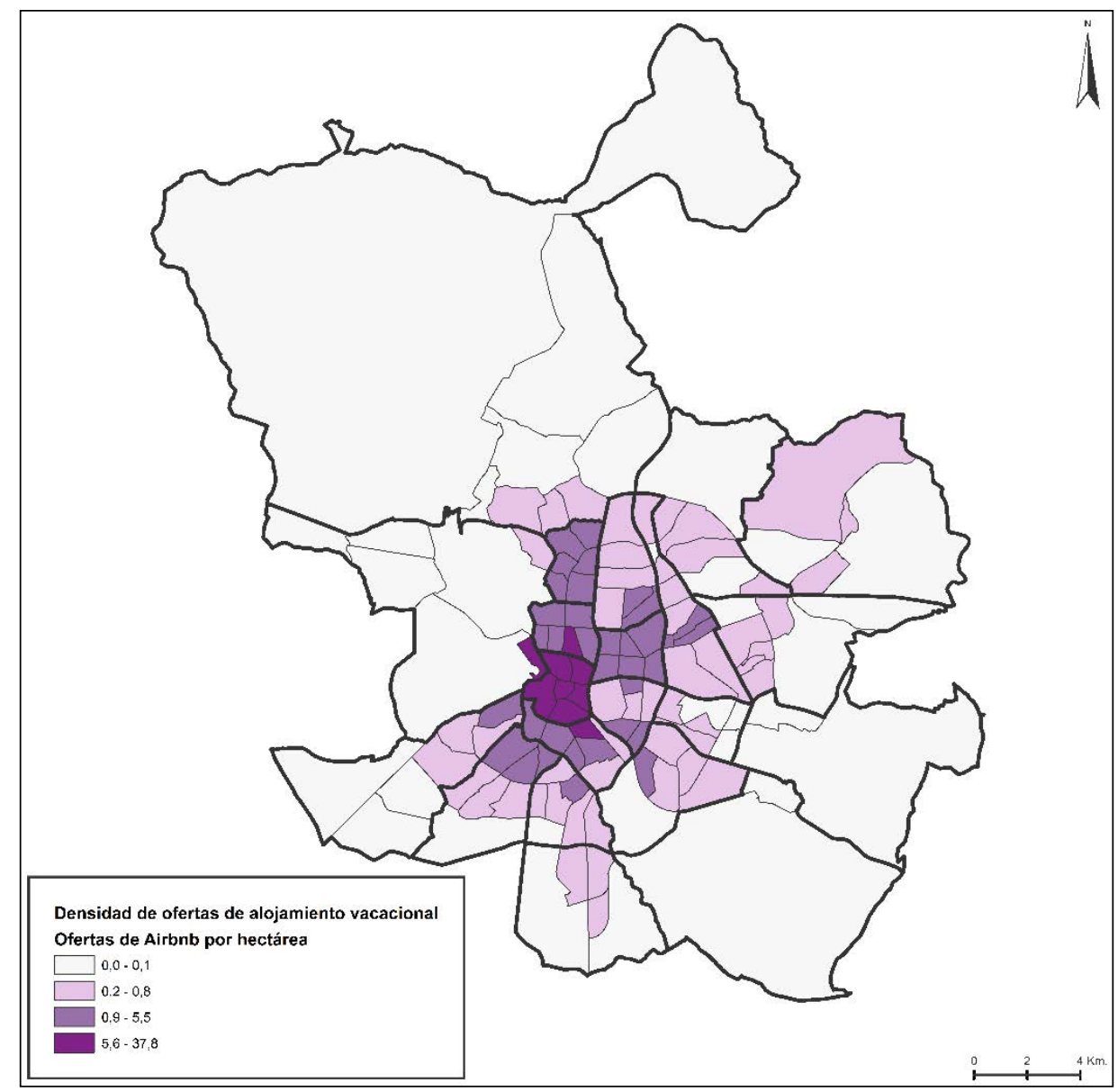

Figura 3. Mapa del número de ofertas de Airbnb por hectárea en Madrid. Fuente: elaboración propia a partir de DataHippo, datos de junio de 2018.

La tercera corona, con valores bajos de densidad de vivienda turística por hectárea, es una extensión de la segunda, pero con densidades menores. En esta corona, se encuentran desde los barrios de Peña Grande y El Pilar en el norte, pasando por los barrios orientales de Niño Jesús, Las Ventas y Jerónimos, hasta llegar al sur del municipio donde destacan: Moscardó, Zofío y Vista Alegre. Por último, queda una cuarta corona a modo de remanente donde la densidad de viviendas turísticas es apenas testimonial como sucede en los Cascos históricos de Vallecas y Vicálvaro. 
A continuación, se analiza el patrón espacial del alquiler turístico ofertado mediante la herramienta Optimized Hot Spot Analysis de ArcGIS, que nos permite detectar los puntos calientes estadísticamente significativos. De esta forma, se ha podido comprobar cuáles son los barrios donde se concentran las ofertas del alquiler de corta duración mediante la visualización de puntos calientes estadísticamente significativos. El resultado obtenido es un gran clúster espacial como único punto caliente de valores elevados (figura 4), el cual tiene una importancia estadística relevante con un nivel de confianza del 99\%. Igualmente, y gracias a los resultados obtenidos mediante el índice I de Moran, se demuestra que la distribución de los alquileres turísticos no es aleatoria ni se encuentra disgregada, sino que está muy clusterizada. Así pues, los resultados del análisis I de Moran (figura 5) nos da un p-valor de 0,0000 y una puntuación Z 15,5089 lo que nos permite desestimar la premisa de que la distribución de Airbnb presenta un patrón aleatorio, y por tanto, aceptar la alternativa, con lo que se puede afirmar que la distribución espacial de Airbnb se encuentra fuertemente concentrada.

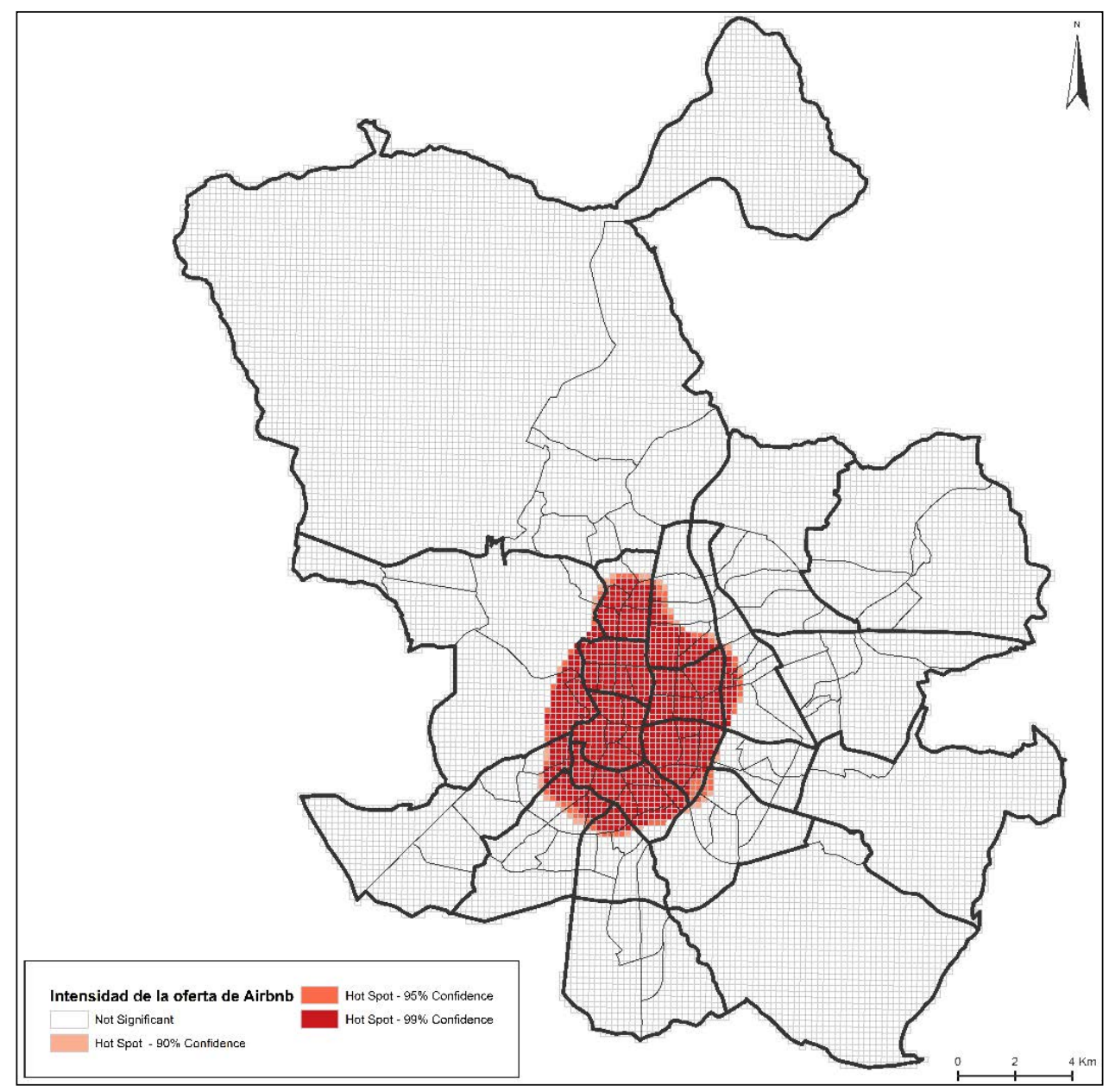

Figura 4. Mapa de puntos calientes estadísticamente significativos de la oferta de Airbnb en el municipio de Madrid. Fuente: elaboración propia a partir de DataHippo, datos de junio de 2018. 


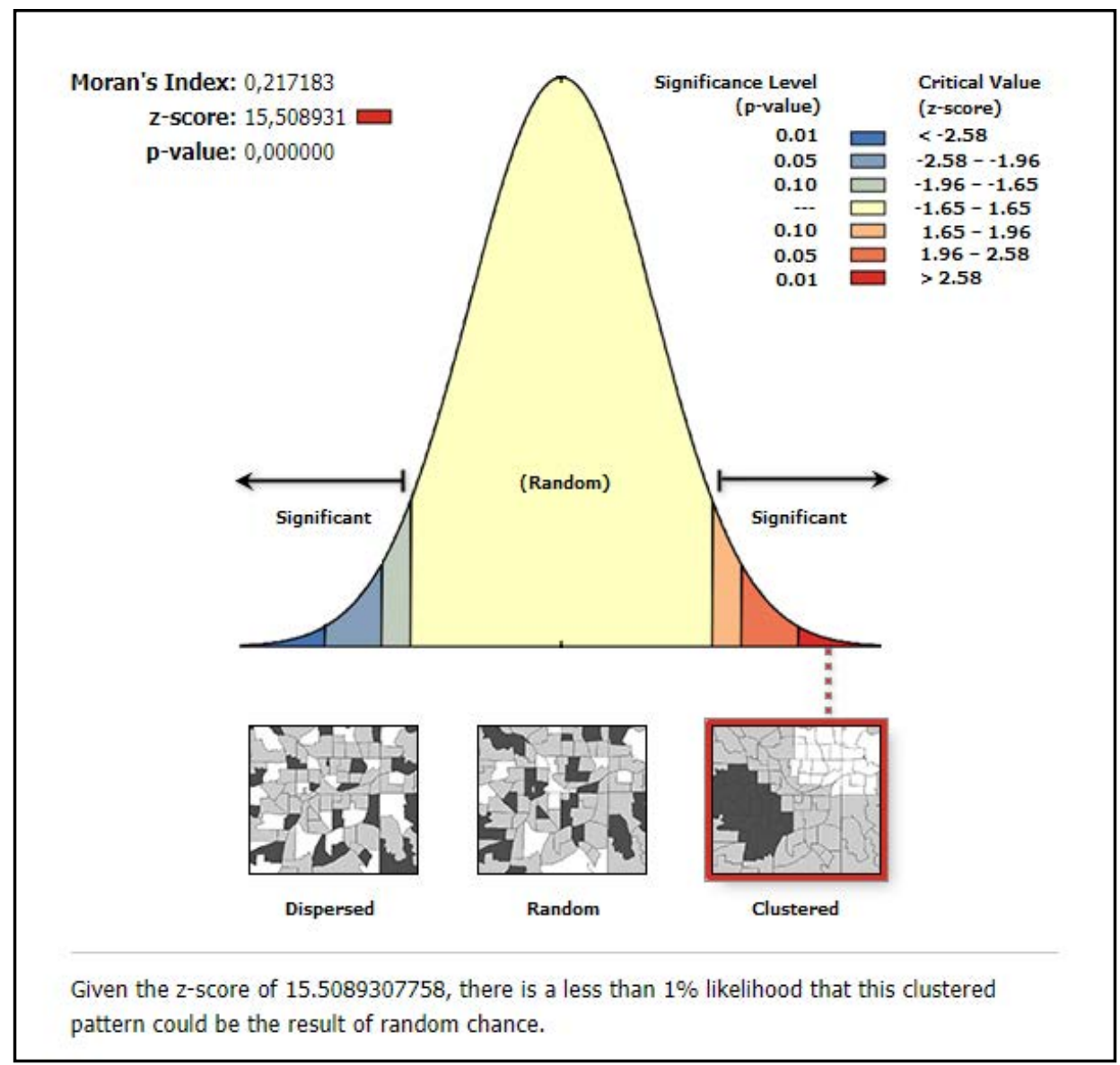

Figura 5. Índice I de Moran sobre la oferta de Airbnb en el municipio de Madrid. Fuente: elaboración propia a partir de DataHippo mediante ArcGIS, datos de junio de 2018.

La distribución espacial de los alquileres ofertados por Airbnb en unos lugares concretos de la ciudad se debe principalmente, aunque no exclusivamente, a unas causas subyacentes. Es decir, tienden a situarse allí donde se localizan los principales atractivos turísticos urbanos, que precisamente son los principales elementos explotados por el alquiler turístico, así como en lugares que no tienen por qué ser turísticamente relevantes, pero que sí tienen la infraestructura necesaria como para permitir un acceso rápido a los puntos de interés (Deboosere et al., 2019). En la figura 6, donde se muestra el análisis de la orientación de las ofertas de Airbnb mediante la herramienta Directional Distribution (Standard Deviational Ellipse) de ArcGIS -cálculo de la elipse de desviación estándar de las entidades estudiadas-, se puede observar como la orientación del alquiler turístico parece tender hacia el noreste del distrito Centro. Sin embargo, y gracias al centro medio ponderado, se ha podido comprobar que la oferta de Airbnb, tan asentada en el distrito Centro, no pretende salir del casco histórico. Pues si bien en el año 2010, parecía avanzar tímidamente hacia el noreste, como también indica la elipse, en el 2014 retrocede hacia el centro, mientras que en el año 2018 vuelve aún más hacia el corazón de la ciudad de Madrid. Confirmando con ello el sólido asentamiento de Airbnb en el distrito Centro, siendo su principal nicho de explotación productiva. 


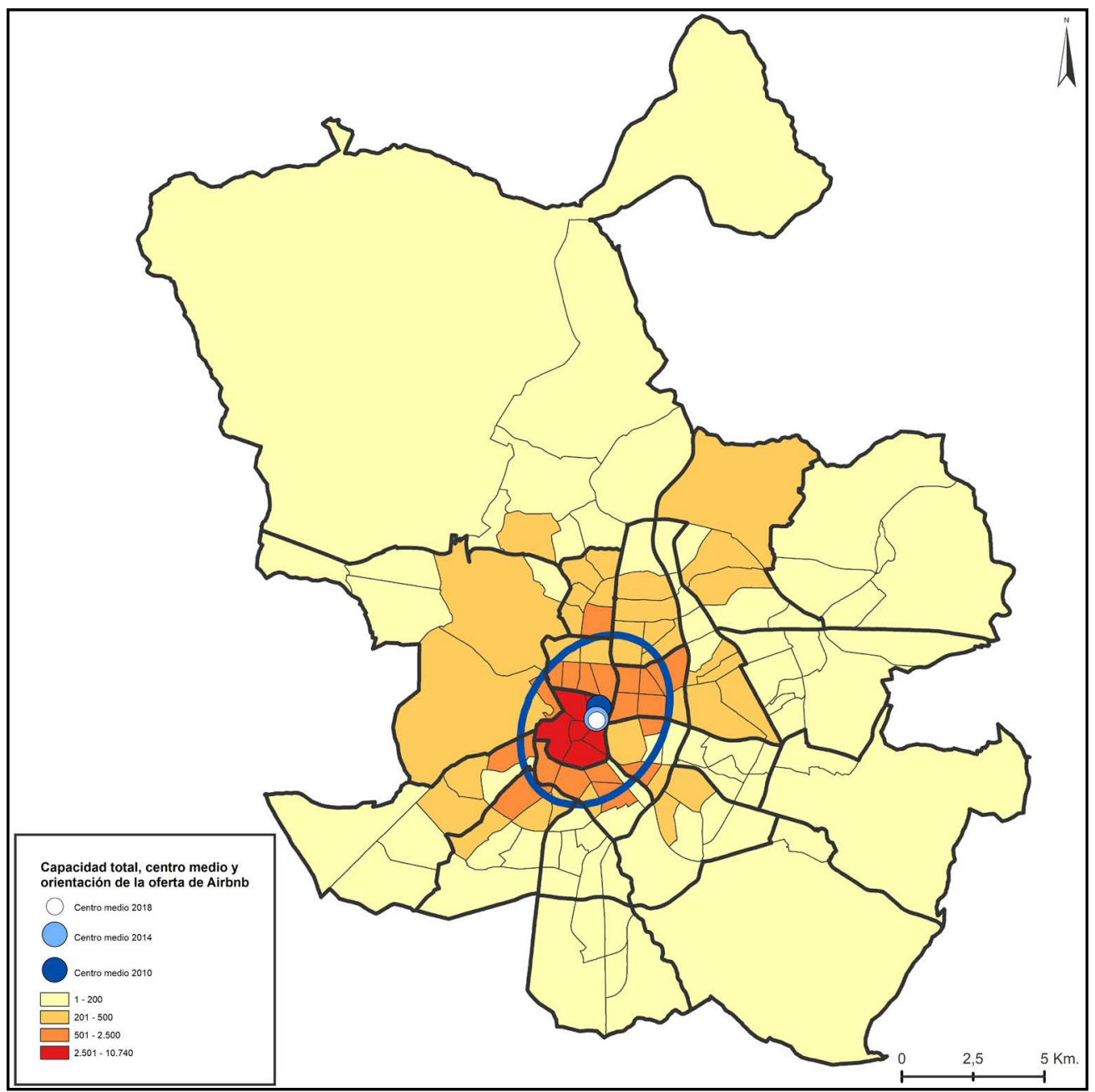

Figura 6. Mapa sobre el total de plazas ofertadas en Airbnb por barrio y orientación de la oferta. Fuente: elaboración propia a partir de DataHippo, datos de junio de 2018.

\subsection{Mutaciones en torno a la vivienda: incidencia de la mercantilización turística de la vivienda sobre los precios del alquiler residencial}

La ciudad, como centro de acumulación de recursos, capital humano y monetario resulta ser uno de los marcos más favorables para la expansión del mercado inmobiliario. Asimismo, la economía política del capitalismo neoliberal ha basculado enormemente en el nexo financiero-inmobiliario que ha sido la causa de la crisis de 2008, pero también paradójicamente una de sus soluciones (Benach y Albet, 2019).

La expansión inmobiliaria ha sido uno de los pilares del capitalismo español, el cual se apuntalaba sobre el mundo financiero mediante el endeudamiento y sobre la actividad turística como mecanismo de absorción de lo que resultó ser una sobreoferta inmobiliaria (Murray, 2015). En el ciclo desarrollista iniciado en 1995, durante el cual se fue inflando la burbuja que acabaría estallando en 2008, la vivienda se conformó como pieza central de la economía familiar gracias a la concesión de créditos hipotecarios, así como por el conjunto de políticas 
que se llevaron a cabo por parte del Estado para estimular la expansión inmobiliaria (López y Rodríguez, 2010).

Los antecedentes de la expansión urbana de Madrid se enraízan en la vasta promoción residencial realizada desde mediados del siglo XX (Observatorio Metropolitano, 2007). El suelo urbano-industrial de la Comunidad de Madrid ha pasado de representar el 3,2\% de la superficie de la comunidad en 1956 al 19,5\% en 2005, mientras que en el municipio de Madrid se pasó del 24,5\% en 1956 al 60,2\% en 2005 (Naredo y García Zaldivar, 2008). De este modo, la ciudad de Madrid no ha dejado de crecer, a menudo a través de pulsaciones urbanísticas aceleradas y caóticas, las cuales han dejado tras de sí un tejido urbano difuso, grandes áreas inconexas dedicadas al comercio y al ocio, así como sobredimensionadas infraestructuras de transporte (Observatorio Metropolitano, 2007). El desarrollo económico de Madrid se ha sustentado sobre un conjunto de inversiones en capital fijo de largo plazo, es decir, sobre el circuito secundario. Además, los megaproyectos territoriales, pelotazos urbanísticos y la corrupción han conformado el panorama político-económico del Madrid de las últimas décadas (Arias, 2009; Naredo, 2019).

Desde el estallido de la burbuja inmobiliaria en 2008 se produjo una caída de los precios de la vivienda y de la construcción de viviendas (López y Rodríguez, 2010; Naredo y Montiel, 2011). Sin embargo, la caída de los precios de la vivienda perduró hasta finales del 2012 y a partir de entonces, se mantuvo, hasta que a partir de 2015 los precios se volvieron a disparar. Así, en el primer trimestre de 2018 los precios de venta de la vivienda de segunda mano en algunos distritos de Madrid ya habían sobrepasado el pico de la anterior burbuja, como por ejemplo en el distrito Centro, situado en la actualidad en los $4.832 € / \mathrm{m}^{2}$, cuando en el 2007 se había llegado al cénit en los $4.728 € / \mathrm{m}^{2}$.

Tal como se ha comentado, durante la anterior burbuja uno de los principales temas de debate y confrontación giraba en torno a la compraventa de viviendas y sus elevados precios. Sin embargo, con el estallido de la crisis y el estrangulamiento financiero posterior, la compraventa de viviendas experimentó una caída en picado. Y los conflictos se trasladaron a las viviendas en alquiler, dando pie a lo que se ha denominado la burbuja del alquiler. Esta burbuja se dibuja después de los cambios normativos llevados a cabo en plena crisis -regulación de las SOCIMI y modificación de la Ley de Arrendamientos Urbanos- que han facilitado la penetración de fondos de inversión y especuladores varios (Rodríguez y Espinoza, 2018). De este modo, el mercado del alquiler residencial en Madrid, que había llegado a su cénit en 2007, comenzó su descenso reflejado en el precio medio del alquiler hasta 2015. A partir de ese momento se reinicia la senda del encarecimiento del alquiler de la vivienda. En la figura 7 se puede contemplar la evolución de los precios del alquiler residencial desde el 2007 hasta el 2018 para la ciudad de Madrid, así como para cada uno de los distritos para los años 2007, 2013 y 2018. 


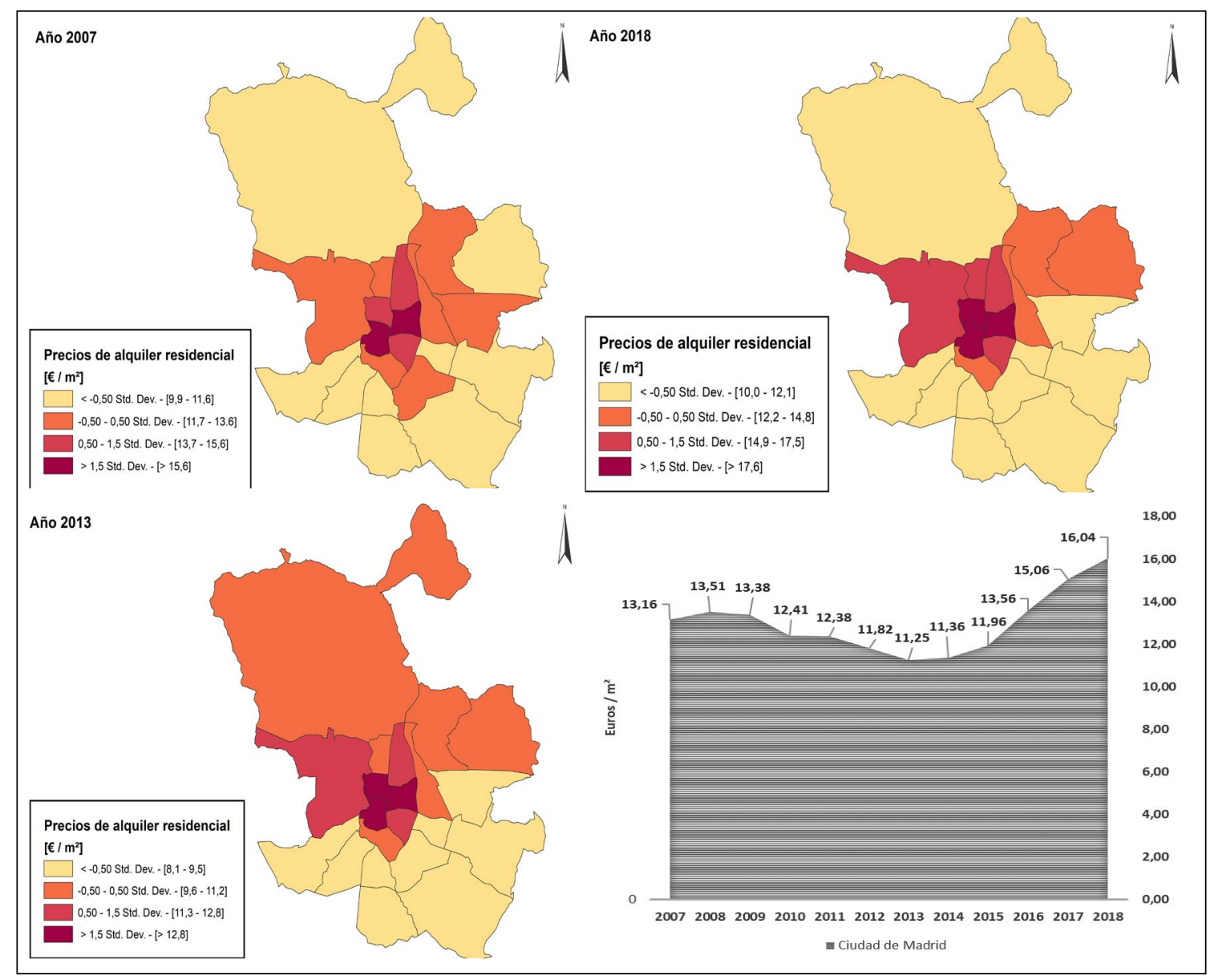

Figura 7. Gráfico sobre el precio del alquiler residencial en la ciudad de Madrid y de sus distritos, años 2007, 2013 y 2018 . Fuente: elaboración propia a partir de datos del Ayuntamiento de Madrid.

El metro cuadrado más caro de Madrid se encuentra en Centro, repuntando desde 2015 con una subida notablemente pronunciada hasta superar los valores previos a la crisis, en la actualidad. El hecho que en 2018 el precio de arrendamiento sea un 21,88\% más elevado que el precio máximo de la pasada burbuja en la ciudad de Madrid, atestigua que de nuevo la ciudad se encuentra bajo la película de una hinchada pompa inmobiliaria. Una muestra clara de ello es la creación del Sindicato de Inquilinos e Inquilinas de Madrid el 2017 ?

Con el objetivo de profundizar en el análisis de la situación actual del mercado del alquiler residencial, se ha recurrido a un paquete de datos extraído de un portal inmobiliario mediante web scraper y publicado en abierto con una extracción de 10.718 ofertas $^{8}$. Esta información ha sido tratada mediante ArcGIS para llevar a cabo un análisis espacial sobre el mercado del alquiler de larga duración. En el 2016, la Comunidad de Madrid contaba con una gran proporción de hogares que vivían en régimen de alquiler (24,5\% del total de hogares).

7. http://www.inquilinato.org/ (acceso 19 de julio de 2019).

8. Datos extraídos por H. Meleiro en marzo de 2018: https://github.com/meneos/TallerMontera34/tree/master/ data. 
De este modo, las viviendas de alquiler representaban el $16 \%$ del parque de viviendas -una cifra que se acerca bastante al 17,36\% del censo de viviendas 2011- (Ministerio de Fomento, 2017). Sin embargo, ante la ausencia de información pública sobre una cuestión tan primordial como es la vivienda en alquiler, los únicos y mejores datos que existen son los que generan las empresas privadas. Empero, estos no son accesibles para la ciudadanía. La opacidad de información sobre la situación de la vivienda del alquiler es otro factor que incide sobre la vulnerabilidad social en torno a la vivienda y que beneficia fundamentalmente a los especuladores. Ante esta situación, los movimientos urbanos en alianza con el movimiento hacker han sido capaces de movilizar gran cantidad de información que ha resultado clave en el debate urbano. Así, tal como sostienen Moranta y Valdivielso (2019) para el caso de las Baleares, los movimientos sociales pueden considerarse como comunidades epistémicas al jugar un papel crucial en la generación de conocimiento.

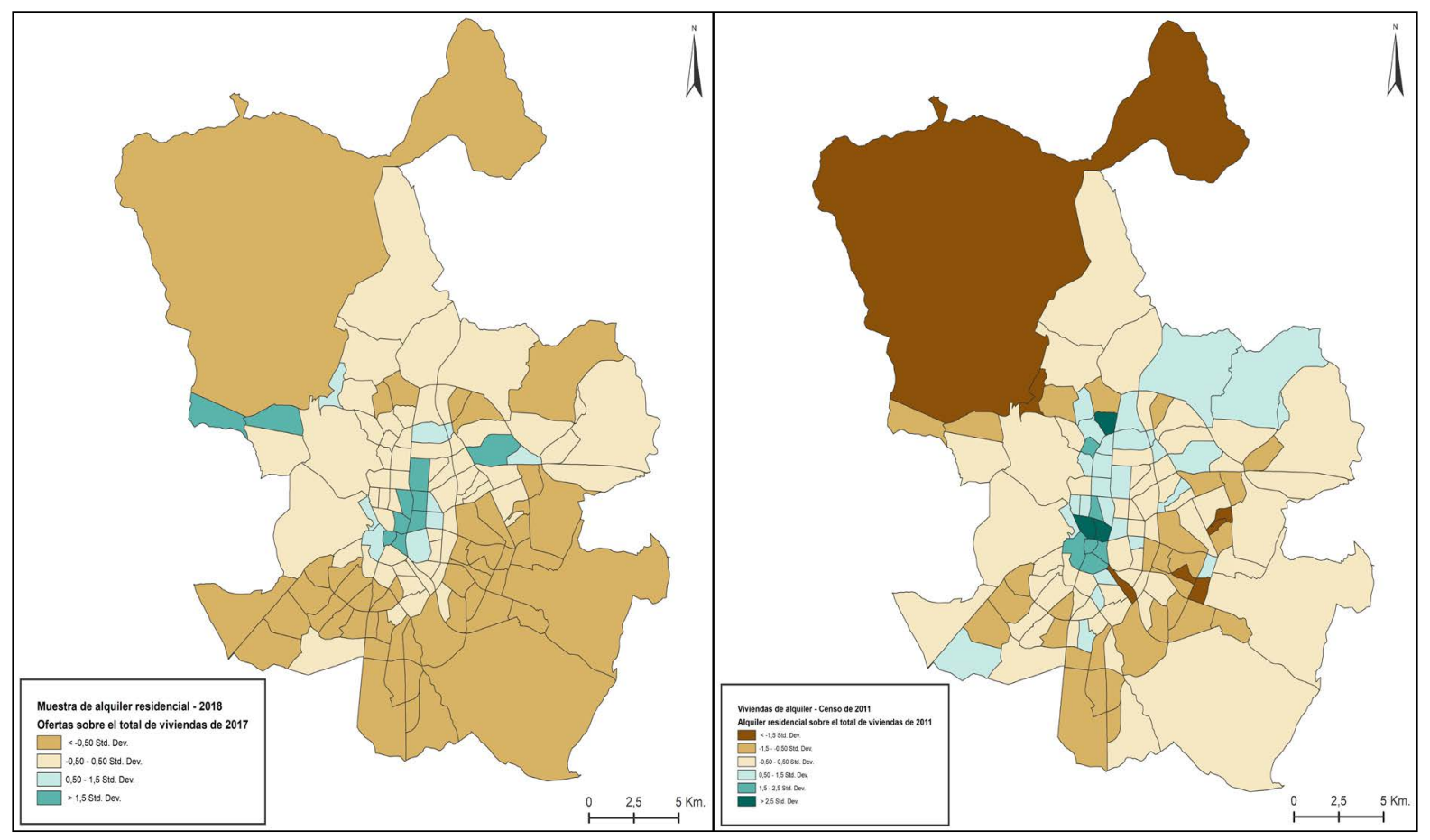

Figura 8. a) proporción de ofertas de vivienda en alquiler residencial sobre el número total de viviendas, 2017; b) proporción de viviendas en alquiler residencial sobre el total de viviendas, Censo 2011. Fuente: elaboración propia a partir de datos del Censo de 2011, INE, 2014 y de la muestra de 2018.

En la octava figura se ha calculado a nivel de barrio el porcentaje de ofertas de alojamientos de alquiler sobre el número de inmuebles de uso residencial del catastro urbano para el año 2017 y se ha contrastado con los datos del Censo de 2011. Los barrios del municipio de Madrid con una mayor oferta de alquiler de larga duración de la muestra analizada son: Recoletos (6,01\%), Piovera (5,32\%), Castellana $(5,10 \%)$, Sol $(4,73 \%)$ y Justicia $(4,22 \%)$. El hecho que el mayor número de ofertas se encuentre en los barrios centrales y septentrionales de Madrid, muestra como en estos barrios el mercado del alquiler residencial es muy dinámico, puesto que la demanda para vivir en estas zonas de la ciudad es elevada, así como la rentabilidad del alquiler. Por otra parte, el menor porcentaje de ofertas de alquiler residencial respecto al número de inmuebles se encuentra en los barrios más meridionales del municipio. En suma, lo que se constata es que el mercado del alquiler de viviendas presenta una gran 
especialización por barrios, coincidiendo el mayor dinamismo de ofertas en aquellos barrios con mayor proporción de viviendas en alquiler. Estos barrios son utilizados por los amos del capital inmobiliario como espacios de extracción de rentas urbanas. Gracias a las modificaciones normativas apuntadas, la rotación y extracción de rentas se ha disparado.

Por último, en la figura 9 se muestra el mapa realizado sobre el volumen de viviendas enteras de Airbnb respecto al total de alquileres residenciales recogidos por el Censo de 2011, siendo la última información disponible sobre la cantidad total de alquiler residencial. De la cartografía se desprende como son los barrios centrales de la ciudad allí donde se ha producido un mayor avasallamiento por parte de Airbnb hacia el uso residencial, si bien es cierto que son muchos los barrios periféricos donde Airbnb ya cuenta con porcentajes del 5\% sobre el alquiler residencial, pudiendo aumentar en el futuro si no se apuesta por la protección del hábitat también en las coronas externas. Asimismo, se debe tener en cuenta la vulnerabilidad socioeconómica de cada uno de los barrios, como los del sur de la ciudad y los más periféricos, tanto al este como al oeste (Méndez y Prada-Trigo, 2014; Observatorio Metropolitano, 2007). Pues la debilidad socioeconómica podrá marcar el nivel de resistencia de dichos espacios para hacer frente a los impactos del alquiler turístico sobre la vivienda, como la subida de los precios del alquiler (Horn y Merante, 2017), lo que desemboca en la expulsión de población permanente y en la gentrificación de la ciudad (Cócola-Gant, 2016; Richards, 2016). No obstante, los futuros devenires permanecen abiertos y cada proceso responderá a la capacidad de resistencia de los barrios, siendo muchos barrios populares de la periferia madrileña escenario de contestación y disputa permanente, como es el caso de Vallecas. Unos barrios, tal como expresa Luís de la Cruz (2018), que sirven de barricada contra la ciudad neoliberal.

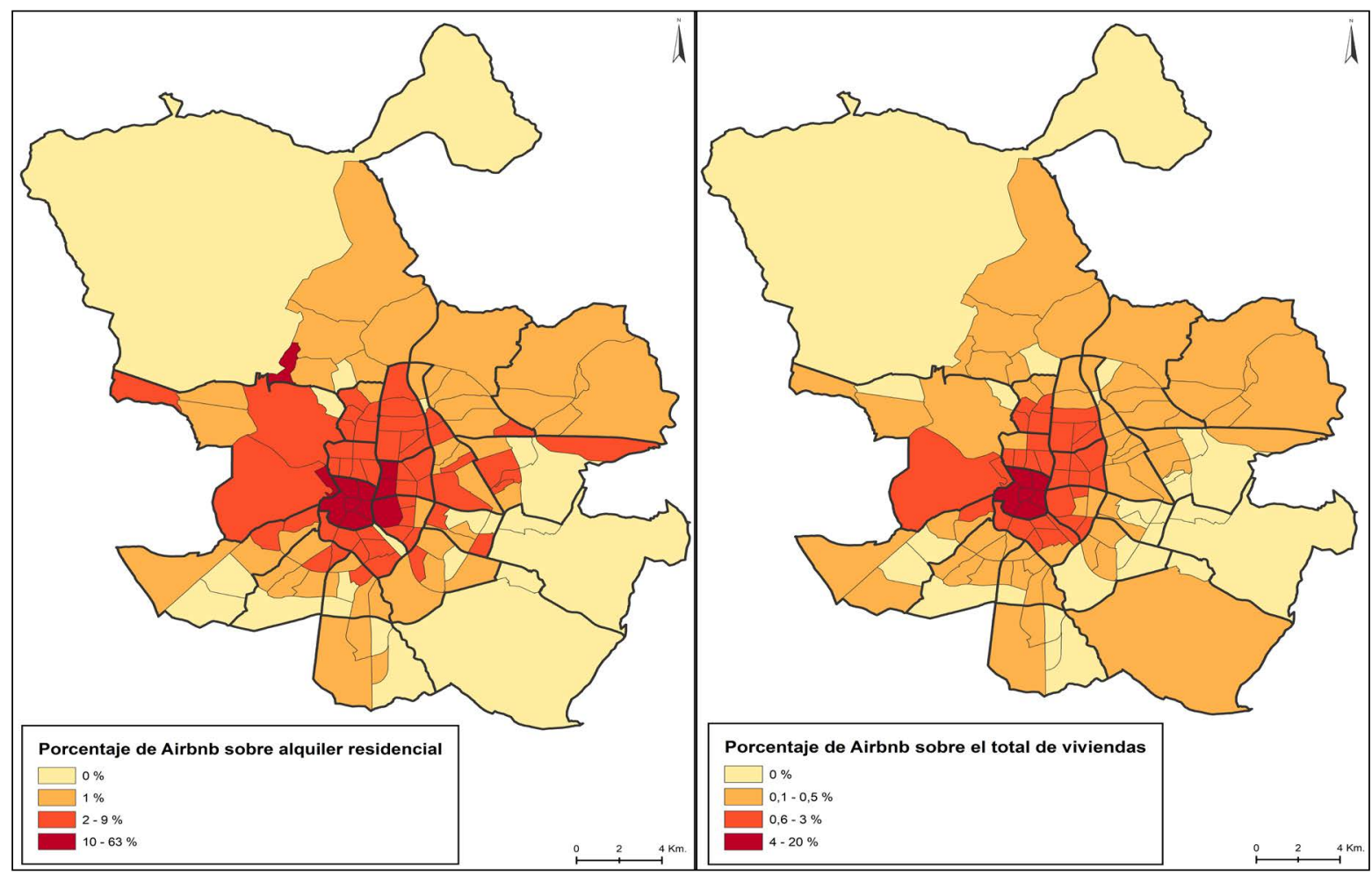

Figura 9. Mapas de las viviendas enteras de alquiler turístico sobe el conjunto de viviendas de alquiler residencial y del total del parque de viviendas a nivel de barrio para la ciudad de Madrid. Fuente: elaboración propia a partir del Censo de 2011 y de DataHippo. 


\section{4. ¿Hacia la regularización del alquiler turístico? Ordenación y regulación del alquiler turístico de viviendas}

La regulación del alquiler turístico de viviendas se ha presentado como uno de los grandes escollos administrativos de los últimos años, quedando su regulación en manos de gobiernos autonómicos y de las grandes ciudades. Además, la irrupción del uso turístico de las viviendas ha abierto un importante debate desde el punto de vista normativo al chocar diferentes niveles administrativos y ámbitos competenciales (Román et al., 2017). De este modo, las sucesivas modificaciones de la Ley 29/1994 de Arrendamientos Urbanos (Ley 4/2013, de 4 de junio, de medidas de flexibilización y fomento del mercado del alquiler de viviendas y Real Decreto-ley $21 / 2018$ de medidas urgentes en materia de vivienda y alquiler) excluyen el alquiler turístico de la regulación básica estatal (Román et al., 2017).

Ello se debe en gran medida a la falta de un consenso político de mínimos sobre la problemática surgida por los cambios de uso de la vivienda, ni de cuáles son sus causas, y por tanto, qué soluciones deberían aplicarse. Por este motivo, y en función de la lectura política que se haga de los conflictos de la vivienda y la problemática de la mercantilización turística de la vivienda, los gobiernos de las grandes ciudades europeas y españolas han intentado regular el uso turístico de la vivienda desde la eclosión del fenómeno Airbnb. Dicha regulación se ha enfocado desde tres perspectivas: prohibición, laissez-faire, regulación con ciertas restricciones (Blázquez et al., 2008; Gil y Sequera, 2018; González, 2019; Nieuwland y Van Melk, 2018).

La hegemonía del discurso neoliberal ha desterrado todo aquel proceder que no apueste por la fuga hacia adelante en pos de la máquina de crecimiento urbano-turístico. De esta manera, el crecimiento turístico-inmobiliario se ha instaurado como la única vía de la economía española, sin alternativa posible en el espectro político actual (Murray, 2015). Así, la ideología abanderada de la rentabilidad corporativo-financiera desprecia segmentos enteros de la sociedad, particularmente las clases populares, que han sido también las más castigadas por la crisis (CCOO, 2019). La extracción de rentas por desposesión se ha impuesto al derecho a la vivienda (como extensión del derecho a la ciudad) (Madden y Marcuse, 2016), mediante el círculo maldito que se inició con las hipotecas para todos, continuó con la epidemia de los desahucios y que actualmente se encuentra en la extensión de la mercantilización turística de la vivienda (Rodríguez y Espinoza, 2018). La mercantilización turística de la vivienda se enfrenta a resistencias sociales que defienden el derecho a la vivienda. Una muestra de estas resistencias es la Red SET de ciudades y regiones del Sur de Europa ante la Turistización (Pardo, 2018). Estos movimientos combaten la consideración de la ciudadanía exclusivamente como consumidores y la subyugación de la ciudad al rol de mercancía. De este modo, dichos movimientos defienden algo que hoy puede considerarse como revolucionario: la desmercantilización de la vida urbana (Brenner et al., 2012). Así, la regularización del uso de la vivienda como hábitat, no es ningún ataque al turista -como a menudo se señala-, sino una protección al habitante y a la calidad vital de la ciudad, que también es del turista, pues él a su vez, también es ciudadano en su propio territorio.

El análisis de la legislación sobre el uso turístico de la vivienda de la Comunidad de Madrid demuestra la flexibilización normativa para dar cabida a las nuevas fórmulas de mercantilización turística, particularmente a partir de la aprobación del Decreto 79/2014 de 10 de 
julio ${ }^{9}$, que muestra la hegemonía de los intereses del capital financiero-inmobiliario y turístico. Entre las razones esgrimidas en el Decreto para la regularización flexible de las VUT (Viviendas de Uso Turístico), se encuentran que la Comunidad de Madrid parte de la conveniencia, tal como se explicita en el preámbulo del decreto, de rentabilizar al máximo las propiedades inmobiliarias, de la urgencia por proteger los derechos de los usuarios y consumidores turísticos de Madrid, y de conseguir nuevas vías de inversión mediante la creación de nuevas empresas sobre la base de los principios de la liberalización. De manera explícita, el proyecto político planteado en el decreto es poner a trabajar el parque de viviendas madrileño a pleno rendimiento. Una auténtica declaración de principios de la ciudad como mercancía y de la vivienda como eje articulador de la extracción de rentas urbanas en favor del capital inmobiliario.

El Decreto 79/2014 apunta que para tener la condición de VUT la vivienda deberá estar amueblada y equipada de tal forma que su uso pueda ser inmediato. Además, las viviendas de uso turístico no podrán utilizarse como residencia permanente y deberán ser cedidos en su totalidad para fines turísticos a cambio de un precio. En consecuencia, el decreto aniquila toda posibilidad de tener una licencia para realizar un uso turístico bajo los términos de la economía colaborativa, imposibilitando alquilar una habitación de la vivienda principal en la que se reside. Una vía que contradice la regulación en otras ciudades, donde solamente se permite la comercialización turística de habitaciones de viviendas principales o la comercialización de la vivienda tan solo unos meses a lo largo del año (Nieuwland y Van Melik, 2018). Igualmente, todo propietario que se dedique al alquiler turístico será visto como un empresario desde el primer día, al quedar eliminado el plazo de tres meses establecido hasta entonces ${ }^{10}$. Ello significa, tal como denunciaron los movimientos urbanos, que dicha regulación eliminaba cualquier trazo de economía colaborativa y que en su lugar apostaba por la profesionalización de la actividad $^{11}$. Por otro lado, se establece que, si todas las viviendas de un edificio se encuentran bajo el uso turístico y pertenecen al mismo propietario, se le aplicará la normativa de apartamentos turísticos. De forma que no solo no hay ninguna medida para impedir que un edificio se convierta en una «hospedería», sino que además aportan un cómodo refugio legal para ello.

Por su parte, el gobierno municipal de Madrid -encabezado por Manuela Carmena (alcaldesa por el partido "Ahora Madrid»)- ha aprobado en 2019 un nuevo Plan Espacial de regulación del uso de servicios terciarios en la clase de Hospedaje (PEH) ${ }^{12}$. La actuación del gobierno municipal debe encuadrarse en las políticas llevadas a cabo por las llamadas ciudades del cambio (p.ej. Barcelona, Madrid, A Coruña, Zaragoza, Palma), entendidas como aquellas con gobiernos surgidos de la contestación del 15M (Roth et al., 2019). El PEH parte del diagnóstico de la creciente expulsión de residentes y la pérdida del uso residencial de las

9. Decreto 79/2014, de 10 de julio, del Consejo de Gobierno, por el que se regulan los apartamentos turísticos y las viviendas de uso turístico de la Comunidad de Madrid.

10. Aprobamos el nuevo Decreto que regula las viviendas de uso turístico http://www.comunidad.madrid/ noticias/2019/04/09/aprobamos-nuevo-decreto-regula-viviendas-uso-turistico

11. Se acabó el margen de 90 días para los pisos turísticos: la Comunidad de Madrid aprueba su decreto sobre VUT. (9 de abril de 2019). Somos Malasaña. [En línea]. Disponible en: https://somosmalasana.elperiodico. com/decreto-comunidad-madrid-plazo-de-90-dias-viviendas-turisticas/

12. Plan Especial de Regulación del uso de Servicios Terciarios en la clase de Hospedaje (PEH) del Ayuntamiento de Madrid. BOLETín OFICIAL DE LA COMUNIDAD DE MADRID. Núm. 95 de 23 de Abril de 2019. 
viviendas, relacionado con la incidencia de las inversiones de fondos de inversión que acaparan inmuebles por su rentabilidad turística. Los propósitos del PEH son zonificar para difundir la centralidad y reactivar las funciones residenciales del distrito Centro, así como de las áreas altamente terciarizadas. Así, su actuación limita los usos de servicios de hospedaje en los distritos Centro, Arganzuela, Retiro, Salamanca, Chamartín, Tetuán, Chamberí, Moncloa-Avaraca, Latina, Carabanchel y Usera. Como se puede observar en la figura 10, el PEH delimita tres anillos respecto del centro de la ciudad, de forma que la regulación sobre el uso terciario de la vivienda varía en cada uno de los distritos mencionados y si la implantación del uso terciario en clase de hospedaje se implanta en la totalidad de la edificación o únicamente en una parte de la misma. Los principales criterios de este régimen de uso son: la cualificación del suelo, los niveles de protección arquitectónica y patrimonial, y la existencia de un acceso independiente en el caso de su implantación en parte de la edificación.

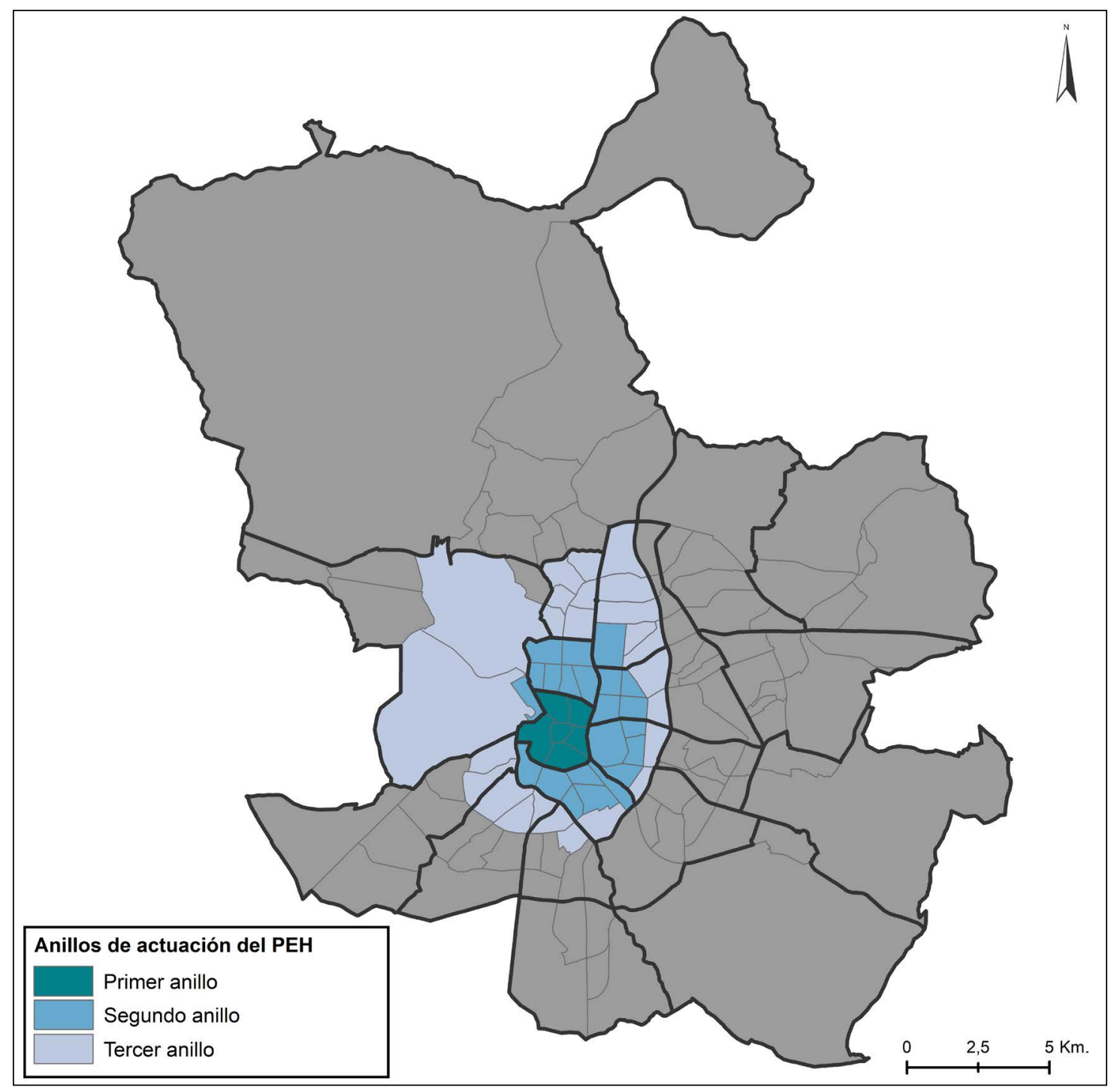

Figura 10. Mapa sobre los distritos contemplados por el PEH. Fuente: elaboración propia a partir del PEH. 
Tal como hemos apuntado, la actuación del PEH varía por anillos y se instituye bajo el objeto, según se describe en el propio plan, de preservar el uso residencial en las zonas centrales de la urbe y limitar la sustitución del uso residencial por el terciario. En el caso del primer y el segundo anillo, acogiendo la totalidad del distrito Centro y sus alrededores, se establece que en los edificios de uso residencial sea necesario que exista un acceso independiente para poder establecer un uso terciario. Mientras que, en el tercer anillo, los edificios residenciales se mantienen bajo la regulación vigente, si bien se exige que aquellos edificios que no admiten otros usos terciarios deban tener también un acceso independiente ${ }^{13}$.

El Ayuntamiento de Madrid ha mostrado en un primer momento que su preocupación principal para llevar a cabo el PEH, es la amenaza que entiende que existe sobre el uso residencial de la vivienda tras el aterrizaje de Airbnb y compañías similares. Sin embargo, el consistorio también ha expresado que su intención es promover que la airbnbficación se extienda a otras zonas de la ciudad mediante su descentralización. De forma que el compromiso detrás de la PEH no parece muy sólido, pues más que combatir el problema, lo que pretende es traspasarlo de un espacio a otro de la ciudad. Dando como resultado previsible que las viviendas residenciales de las coronas periféricas de la ciudad de Madrid puedan ser mercantilizadas como hospederías turísticas con las consecuentes expulsiones de población. Asimismo, conviene resaltar que los anillos periféricos no son socialmente homogéneos ya que contrastan, a grandes rasgos, unos barrios ricos en el norte con los más pobres del sur, y que por lo tanto, la incidencia social de la mercantilización turística de la vivienda será desigual (Ruíz Chasco, 2018).

Mediante la anterior cartografía presentada, las zonas más afectadas por la airbnbificación son los barrios situados en el corazón de la ciudad de Madrid (figura 5). Aunque si bien el alquiler turístico ha tomado como bastión primigenio el casco histórico, no significa que no pueda trasladarse asimismo a otros distritos de la ciudad de Madrid, dejando florecer sus problemáticas allí donde consiga germinar, que con la ayuda del $\mathrm{PEH}$, sería en las coronas periféricas de la metrópolis.

\section{CONCLUSIONES}

La fuerte expansión protagonizada por el alquiler turístico surge a través de la destrucción creativa a raíz de la crisis global de 2008 (Harvey, 2019). Desde entonces, la consideración de la vivienda como un recurso que debe monetizarse y, que habitarlo es sinónimo de infrautilización, no ha dejado de crecer.

El impacto del alquiler turístico se ha extendido por todo el globo, aunque de manera desigual, siendo en Europa donde más ha calado, y sobre todo, en sus metrópolis y espacios de litoral. Es decir, la airbnbificación se ha producido fundamentalmente en las zonas ya especializadas en el turismo. Entre ellas se encuentra la ciudad de Madrid, donde se ha concentrado

13. Casado, D. (27 de marzo de 2019). Así funciona la ley 'anti Airbnb' aprobada por el Ayuntamiento de Madrid. Somos Malasaña. [En línea]. Disponible en: https://somosmalasana.elperiodico.com/preguntasrespuestas-ley-anti-airbnb-ayuntamiento-madrid/ 
en el propio corazón de la urbe y a partir de allí se ha dispersado gradualmente en forma de mancha de aceite. Asimismo, la distribución del alquiler turístico, que sigue un patrón espacial de centro-periferia, se orienta hacia los barrios del noreste de la ciudad, aunque su lugar de acción sigue estando en el casco histórico, siendo su principal centro de explotación y del cual no se desprenderá por iniciativa propia.

Los espacios donde se produce la mayor confrontación entre el alquiler residencial y la mercantilización turística de la vivienda son en los barrios de Centro y Fuente la Reina, así como en los barrios de Imperial, Palos de Moguer, Jerónimos, Recoletos, Goya, Castellana, Trafalgar, Almagro y Argüelles. Se trata de barrios muy distintos socioespacialmente, lo que dificulta establecer cómo afectaran los impactos de Airbnb en la población. Igualmente, se debe tener en cuenta la evolución futura de Airbnb hacia la periferia, siendo el territorio por el qué el PEH apuesta para que el uso turístico se asiente en las viviendas, dejando al desamparo a los habitantes y hábitats del extrarradio de la ciudad de Madrid. A la vez que se abre la veda para los amos del capital para obtener rentas con mayor facilidad en estos nuevos espacios mediante la explotación inmobiliaria.

La distribución geográfica de Airbnb ha permitido un contundente asentamiento en Madrid, pues ha tenido plena libertad para expandirse hacia dónde y cómo ha querido. Empero, las consecuencias de esta actividad también han volado con total libertad, como la subida de los precios de la vivienda, la gentrificación y la expulsión de población residente (Sequera y Janoschka, 2015); poniendo sobre la palestra a su vez, las contradicciones de los llamados ayuntamientos del cambio. Prueba de ello, es que los precios de venta de la vivienda de segunda mano se sitúan ya en 2018, en el distrito Centro de Madrid, por encima de los valores alcanzados en 2007, antes del estallido de la burbuja inmobiliaria, próximas a 5.000€/ $\mathrm{m}^{2}$. De igual manera, los precios del alquiler residencial o de larga duración en Madrid han experimentado un rápido encarecimiento, situándose en 2018 un 22\% por encima del cénit de la burbuja inmobiliaria. Adicionalmente, el cálculo de la oferta de alquiler residencial muestra que ésta tiende a ser menor en los barrios meridionales del municipio, que a su vez son los barrios de las clases populares. Por todo ello, entendemos que es necesario que los poderes públicos dejen de priorizar la mercantilización turística de la vivienda, poniendo en primer plano a los habitantes y a la habitabilidad de la ciudad, asegurando con ello el acceso a la vivienda a toda la población.

El neoliberalismo ha propiciado el consumo de la cultura autóctona generada por los habitantes, así como del mismo territorio, para alimentar a la industria turística. Por su parte, el alquiler turístico ha conseguido ir un paso más allá, al permitir que el turismo consiga penetrar en las propias moradas, en busca de una experiencia más auténtica (Gil, 2019). Sin embargo, el resultado de ese intento por captar la vivencia más única y verdadera del lugar visitado, se torna en falsedad, porque la vivienda deja de ser hábitat para convertirse en «hospedaje», y la ciudad se convierte en un espacio de representación cuya finalidad es atraer al consumidor-turista a través de una superficialidad amable. La gran contradicción que encierra el alquiler turístico es que, buscando la autenticidad, despoja a la ciudad de su contenido social, el cual resulta ser el principal rasgo distintivito del lugar. 
La normativa flexibiliza la mezcla de usos residenciales y turísticos, siendo la norma de la Comunidad de Madrid un claro ejemplo de laissez-faire (Romero, et al., 2015), mientras que el intento del Ayuntamiento se encuadra en las políticas que permiten el uso turístico de la vivienda con restricciones, que en este caso se lleva a cabo mediante la zonificación (Nieuwland y Van Melk, 2018). El tímido intento de zonificación del PEH se limita a extender los usos hacia anillos periféricos respecto del distrito Centro, como medida compensatoria de su contención del alquiler turístico en los barrios más afectados del centro de la ciudad. Pese a la moderación de dicha propuesta, su vigencia está hoy en día en entredicho por parte del nuevo gobierno municipal conservador surgido de las elecciones de 2019 , que opta por la vía ultraliberal (Otero, 2019).

Las principales limitaciones de muchas de las investigaciones que se han llevado a cabo sobre el proceso de airbnbificación giran en torno a la polarización entre trabajos excesivamente cuantitativos, como el nuestro, frente otros fundamentalmente cualitativos. Por este motivo, una de las vías de trabajo que podrían solventar dichas limitaciones sería a través de propuestas metodológicas eclécticas en las que se combinen métodos cuantitativos con cualitativos. Otra de las limitaciones gira en torno a la generalización del conjunto de la ciudad que podría superarse en un futuro mediante el estudio en profundidad de los barrios. Asimismo, uno de los principales escollos, señalados en el artículo, giran en torno a la debilidad institucional en la elaboración y difusión de información relativa a la vivienda, como por ejemplo la baja calidad del Censo de 2011, así como la profusión de estudios sesgados a favor de intereses económicos. Así pues, una de las líneas futuras de trabajo a asumir debería ser la confección de información pública, independiente y solvente sobre la cuestión de la vivienda.

\section{REFERENCIAS BIBLIOGRÁFICAS}

Aalbers, M.B. (2016). The financialization of housing: A political economy approach. London: Routledge.

Arias, F. (2009). Megaproyectos urbanos madrileños ¿Quién manda en Madrid?: las cuatro torres y el «señor de los anillos». En Aguilera, F. y Naredo, J.M. (Eds.). Economía, poder y megaproyectos (pp. 181-208). Lanzarote: Fundación César Manrique.

Ayuntamiento de Madrid. Aprobado el Plan Especial para la regulación de uso terciario en su clase de Hospedaje. [En línea]. Disponible en: https://diario.madrid.es/blog/notasde-prensa/aprobada-definitivamente-la-regulacion-para-viviendas-de-uso-turistico/ [Consulta 19/04/2019].

Ayuntamiento de Madrid. Banco de datos. [En línea]. Disponible en: http://www- 2.munimadrid.es/CSE6/control/menuCSE?filtro=NS\&tablaSerie=SERIES [Consulta 04/08/2018].

Benach, N. y Albet, A. (2019). David Harvey. La lógica espacial del capitalismo. Bacerlona: Icaria.

Blanco-Romero, A., Blázquez-Salom, M. y Cànoves, G. (2018). Barcelona, housing rent bubble in a tourist city. Social responses and local policies. Sustainability, 10, 6, 1-18.

Blanco-Romero, A., Blázquez-Salom, M., Morell, M. y Fletcher, R. (2019). Not tourism-phobia but urban-philia: understanding stakeholders' perceptions of urban touristification. Boletín de la Asociación de Geógrafos Españoles, 83, 1-30. 
Brenner, N., Marcuse, P. y Mayer, M. (Eds.) (2012). Cities for people, not for profit. London: Routledge.

Cabrerizo, C. (2016). La ciudad negocio. Turismo y movilización social en pugna. Madrid: Cisma. Cañada, E. y Murray, I. (Eds.). (2019). Turistificación global. Perspectivas críticas en turismo. Barcelona: Icaria Editorial.

Carpintero, O. (Dir.) (2015). El metabolismo económico regional español. Madrid: FUHEM Ecosocial.

Casado, D. (27 de marzo de 2019). Así funciona la ley 'anti Airbnb' aprobada por el Ayuntamiento de Madrid. Somos Malasaña. [En línea]. Disponible en: https://somosmalasana.elperiodico.com/preguntas-respuestas-ley-anti-airbnb-ayuntamiento-madrid/] [Consulta 12/05/2019].

CCOO (2019). El estado "social» de la Comunidad de Madrid. Indicadores básicos de protección y cohesión social. http://www.madrid.ccoo.es/6f4909f16c971b6fce7b7ee921e16a37000045.pdf

Cócola-Gant, A. (2016) Alojamiento turístico y desplazamiento de población. Contested cities, 3, 1-13.

Cócola-Gant, A. (2019). Gentrificación turística. En Cañada, E. y Murray, I. (Eds.), Turistificación global. Perspectivas críticas en turismo (pp. 291-308). Barcelona: Icaria.

Colomb, C. y Novy, J. (Eds.) (2016). Protest and Resistance in the Tourist City. London: Routledge.

Crommelin, K. Troy, L., Martin, C. y Pettit, C. (2018). Is Airbnb a Sharing Economy Superstar? Evidence from Five Global Cities. Urban Policy and Research 36, 429-444.

Cruz, L. (2018). Barrionalismo. Madrid: Decordel.

Christophers, B., Leyshon, A. y Mann, G. (2017). Money and finance after the crisis: critical thinking for uncertain times. Oxford: Wiley-Blackwell.

Deboosere, R., Kerrigan, D.J., Wachsmuth, D. y El-Geneidy, A. (2019). Location, location and professionalization: a multilevel hedonic analysis of Airbnb listing prices and revenue. Regional Studies, Regional Science, 6(1), 143-156.

Decreto 79/2014, de 10 de julio, por el que se regulan los apartamentos turísticos y las viviendas de uso turístico de la Comunidad de Madrid. Boletín oficial de la Comunidad de Madrid, 180 de 31 de Julio de 2014.

Del Romero, L. (2010). Dos décadas de urbanismo-espectáculo en España: los grandes eventos como motor de cambio urbano. Boletín de la Asociación de Geógrafos Españoles, 53, 309-327.

Fletcher, R. (2011). Sustaining Tourism, Sustaining Capitalism? The Tourism Industry's Role in Global Capitalist Expansion. Tourism Geographies, 3, 443-461, DOI: 10.1080/14616688.2011.570372

Gil, J. (2019). Redistribución económica y precariedad. El caso de los anfitriones de Airbnb. Recerca, revista de pensament i anàlisi, 24(1), 92-113.

Gil, J. y Sequera, J. (2018). Expansión de la ciudad turística y nuevas resistencias. El caso de Airbnb en Madrid. Empiria, 41, 15-32.

González, J.M. (2019). The dispute over tourist cities. Tourism gentrification in the historic Centre of Palma (Majorca, Spain). Tourism Geographies https://doi.org/10.1080/1461 6688.2019.1586986 
Gurran, N. (2018). Global Home-Sharing, Local Communities and the Airbnb Debate: A Planning Research Agenda. Planning Theory \& Practice, 19 (2), 298-304.

Harvey, D. (2014). Diecisiete contradicciones del capital y el fin del capitalismo. Madrid: Traficantes de Sueños.

Harvey, D. (2019). Spaces of Global Capitalism. London: Verso.

Horn, K. y Merante, M. (2017). Is home sharing driving up rents? Evidence from Airbnb in Boston. Journal of Housing Economics, 38, 14-24.

Lefebvre, H. (1968). El derecho a la ciudad. Madrid: Capitán Swing.

López, I. y Rodríguez E. (2010). Fin de ciclo. Financiarización, territorio y sociedad de propietarios en la onda larga del capitalismo hispano (1959-2010). Madrid: Traficantes de sueños.

Madde, D. y Marcuse, P. (2016). In defense of housing. London: Verso.

Méndez, R. (2018). La telaraña financiera. Una geografía de la financiarización y su crisis. Santiago de Chile: RIL editores.

Méndez, R. y Prada-Trigo, J. (2014). Crisis, desempleo y vulnerabilidad en Madrid. Srcipta Nova. Revista Electrónica de Geografía y Ciencias Sociales, 18(474), 1-22.

Milano, C. y Mansilla, J. (coords.). 2018. Ciudad de vacaciones. Conflictos urbanos en espacios turísticos. Barcelona: Pol.len.

Milano, C. y Mansilla, J. A. (2019). La cuestión turística: el activismo turístico y la turistificación de los movimientos sociales. En Cañada, E. y Murray, I. (Eds.) Turistificación global. Perspectivas críticas en turismo (pp. 367-380). Barcelona: Icaria.

Ministerio de Fomento (2017). Observatorio de Vivienda y Suelo. Boletín especial Alquiler Residencial. Madrid: Ministerio de Fomento.

Moranta, J. y Valdivielso, J. (2019). Struggles over tourism degrowth in the Balearic Islands. Journal of Sustainable Tourism, 27(12), 1876-1892.

Morell, M. (2018). Urban tourism via dispossession of ouvre, Labour as a common denominator. Focaal 8(82), 35-48.

Murray, I. (2015). Capitalismo y turismo en España. Del «milagro económico» a la "gran crisis». Barcelona: Alba Sud Editorial.

Naredo, J.M. (2006). Raíces económicas del deterioro ecológico y social. Más allá de los dogmas. Madrid: Siglo XXI España.

Naredo, J.M. y García Zaldivar,R. (coords.) (2008). Estudio sobre la ocupación de suelo por usos urbano-industriales, aplicado a la Comunidad de Madrid. http://habitat.aq.upm. es/oscam/

Naredo, J.M. y Montiel, A. (2011). El modelo inmobiliario español y su culminación en el caso valenciano. Barcelona: Icaria.

Nieuwland, S. y Van Melk, R. (2018). Regulating Airbnb: how cities deal with perceived negative externalities of short-term rentals. Current Issues in Tourism, 1-15 https://doi.org/ 10.1080/13683500.2018.1504899.

Observatorio Metropolitano (2007). Madrid ¿La suma de todos? Globalización, territorio, desigualdad. Madrid: Traficantes de Sueños.

Otero, J. (2019). El nuevo Ayuntamiento de Madrid tumba en solo 10 días ocho medidas del legado de Manuela Carmena. Público 25/06/2019 (https://www.publico.es/politica/ 
ayuntamiento-madrid-siete-medidas-pp-cs-erradicar-legado-manuela-carmena-madrid.html).

Palacios García, A. J. (2008). Fuentes estadísticas sobre la vivienda en España: un obstáculo para el diseño de la política de vivienda. Scripta Nova. Revista Electrónica de Geografía y Ciencias Sociales, 270 (38).

Pardo, D. (2018). Las posibilidades de una red ante la turistización del Sur de Europa, 02/05/2018. Alba Sud. Disponible online: http://www.albasud.org/noticia/es/1034/las-posibilidades-de-una-red-ante-la-turistizaci-n-del-sur-de-europa [Última consulta 20/5/2019].

Plan Especial de Regulación del uso de Servicios Terciarios en la clase de Hospedaje (PEH) del Ayuntamiento de Madrid. Boletín oficial de la Comunidad de Madrid. Núm. 95 de 23 de abril de 2019.

Prada-Trigo, J. (2018). Espacios vulnerables, crisis y «post-crisis económica»: trayectoria y persistencia a escala intraurbana. Scripta Nova. Revista Electrónica de Geografía y Ciencias Sociales, 22(587), 1-23.

Quaglieri, A. y Sánchez, S. (2019). Alojamiento turístico y «economía colaborativa»: una revisión crítica de los discursos y las respuestas normativas. En Cañada, E. y Murray, I. (Eds.) Turistificación global. Perspectivas críticas en turismo (pp. 343-365). Barcelona: Icaria.

Richards, G. El turismo y la ciudad: ¿'hacia nuevos modelos? Revista CIDOB d'Afers Internacionals, 2016, 113, 71-87.

Rodríguez, I. (2001). Vivienda y promoción inmobiliaria en Madrid. Cataluña: Universitat de Lleida.

Rodríguez, R. y Espinoza, M. (2018). De la especulación al derecho a la vivienda. Más allá de las condiciones del modelo inmobiliario español. Madrid: Traficantes de Sueños.

Román Sánchez, I.M., Paulova, N., Nieto González, J.L. y Bonillo Muñoz, D. (2017). La legislación sobre los apartamentos turísticos y viviendas de uso turístico en España, comparativa por comunidades Autónomas. International journal of scientific management and tourism, 3(4), 397-417.

Romero, J., Brandis, D. y Melo, C. (2015). El giro neoliberal de las políticas para la ciudad en España. Balance a partir de los ejemplos de Madrid y Valencia. Boletín de la Asociación de Geógrafos Españoles, 69, 369-386.

Roth, L., Monterde, A. y Calleja-López, A. (Eds.). (2019). Ciudades democráticas. La revuelta municipalista en el ciclo post-15M. Barcelona: Icaria.

Ruíz Chasco, S. (2018). Madrid, de norte a sur: análisis sociológico de las desigualdades sociales y la inseguridad ciudadana en los barrios de Lavapiés y Salamanca (Tesis Doctoral). Universidad Complutense de Madrid, Madrid (https://eprints.ucm.es/49572/1/ T40387.pdf).

Se acabó el margen de 90 días para los pisos turísticos: la Comunidad de Madrid aprueba su decreto sobre VUT. (9 de abril de 2019). Somos Malasaña. [En línea]. Disponible en: $\quad$ https://somosmalasana.elperiodico.com/decreto-comunidad-madrid-plazo-de-90-dias-viviendas-turisticas/ [Consulta 12/05/2019].

Sequera, J. y Janoschka, M. (2015). Gentrification dispositifs in the historic centre of Madrid: a reconsideration of urban governmentality and state-led urban reconfiguration. En Lees, 
L., Shin, H.B. y López-Morales, E. (Eds.), Global Gentrifications. Uneven Development and Displacement (pp. 375-393). Policy Press, Bristol.

Valenzuela, M. (1999). Turismo cultural y políticas urbanas sostenibles en el Casco Histórico de Madrid. Revista de arte, geografía e historia, 2, 389-419.

Wyly, E. (2011). Positively Radical. International Journal of Urban and Regional Research, 35(5), 889-912. 